Çukurova Üniversitesi Mühendislik Mimarlık Fakültesi Dergisi, 35(4), ss. 1031-1046, Aralık 2020 Çukurova University Journal of the Faculty of Engineering and Architecture, 35(4), pp. 1031-1046, December 2020

\title{
Analitik Hiyerarşi Süreci ve Veri Önişleme Yoluyla Türkiye'nin Güç Sistemi Portföyünün Planlanması
}

\author{
Üzeyir FIDAN"1, Mehmet ATAK ${ }^{2}$ \\ ${ }^{1}$ Uşak Üniversitesi, Uzaktan Eğitim Meslek Yüksekokulu, Bilgisayar Teknolojileri Bölümü, Uşak \\ ${ }^{2}$ Gazi Üniversitesi, Mühendislik Fakültesi, Endüstri Mühendisliği Bölümü, Ankara
}

Geliş tarihi: 05.08.2020 Kabul tarihi: 30.12 .2020

\section{Öz}

Bu çalışmada amaç, enerji konusunda dışa bağımlı bir ülke olan Türkiye'nin 2020-2039 yılları arasında ihtiyaç duyacağı elektrik enerjisini karşılayabilecek bir yatırım planı sunmaktır. Elektrik enerjisi üretimi için stratejik yatırım planı sürdürülebilir arz güvenliğinin sağlanması açısından kritik öneme sahiptir. Yatırım planının oluşturulması aşamasında çok kriterli karar verme yöntemlerinden Analitik Hiyerarşi Süreci (AHS) kullanılmıştır. Model oluşturulurken uygulanan bir dizi veri önişleme tekniği sayesinde AHS'nin öznellik yaklaşımı büyük ölçüde ortadan kaldırılarak görece daha nesnel sonuçların elde edilmesi sağlanmıştır. Çalışmaya özgünlük kazandıracak şekilde kullanılan veri önişleme teknikleri ve AHS yöntemiyle Türkiye Cumhuriyeti Enerji ve Tabii Kaynaklar Bakanlığı'nın (ETKB) stratejik hedefleri doğrultusunda bir portföy senaryosu ortaya konmuştur. Araştırma elde edilen portföy senaryosuyla ETKB'nin hedeflerini destekleyecek nitelikte bulgular ortaya koymaktadır. Buna göre, artan ihtiyacı karşılarken kullanılan enerji kaynaklarına göre elektrik üretiminde kömürün \%10,6, doğal gazın \%3, hidroelektrik kullanımının ise $\% 4,3$ azalacağı, rüzgârın $\% 1,68$, güneşin $\% 4,34$ ve jeotermal kullanımının da \%2,98 artacağı öngörülmüştür. Sonuç olarak, yapılan planlama dışa bağımlılık oranını, fosil yakıt kullanım oranını ve emisyon değerlerini düşürürken, yenilenebilir enerji kaynaklarının kullanımını, istihdam potansiyelini ve arz güvenliğini arttırmaktadır. Bu araştırmanın sonuçları ETKB'nin 20 yıllık stratejik planında yer alan hedeflerin tutarlı olduğunu göstermesi açısından büyük önem arz etmektedir.

Anahtar Kelimeler: Sürdürülebilir enerji planlaması, Enerji verimliliği, Karar teorisi, Veri önişleme, Analitik hiyerarşi süreci

\section{Planning Power System Portfolio of Turkey through Analytic Hierarchy Process and Data Preprocessing}

\section{Abstract}

The purpose of this study is to suggest an investment plan for Turkey, which is dependent on foreign energy, that meets Turkey's electrical energy demand between 2020-2039. Strategic investment plan for electricity generation is crucial in terms of ensuring sustainable supply security. Analytical Hierarchy Process (AHP), which is a multi-criteria decision-making method, was utilized to build this investment proposal. Under a series of data preprocessing techniques applied within the model, the subjectivity that is often observed in AHP has been largely eliminated, resulting in relatively more objective results. With the

"Sorumlu yazar (Corresponding author): Üzeyir FIDAN, uzeyir.fidan@usak.edu.tr 
unique data preprocessing techniques and the AHP method applied within the study, a portfolio scenario that is in line with the strategic objectives of the Republic of Turkey Ministry of Energy and Natural Resources has been offered. With the obtained portfolio scenario, the research reveals findings that support the goals of ETKB. Accordingly in proportion to the energy sources used to meet increasing demand, it is predicted that while the use of coal, natural gas and hydroelectric within this production will decrease by $10.6 \%, 3 \%$, and $4.3 \%$ respectively, the use of wind, sun and geothermal will increase by $1.68 \%, 4.34 \%$, and $2.98 \%$ respectively. As a result, the suggested plan reduces the rates of external dependency, fossil fuel use, and emission values while increasing the use of renewable energy sources, employment potential, and security of supply. The results of the research are of great importance in terms of demonstrating that the goals in the 20-year strategic plan of ETKB are consistent.

Keywords: Sustainable energy planning, Energy efficiency, Decision theory, Data preprocessing, Analytical hierarchy process

\section{GíRiș}

Elektrik modern toplumların refah düzeylerinde belirleyici bir öneme sahiptir [1-2]. Günlük yaşamsal faaliyetlerden üretim süreçlerine kadar uzanan geniş çerçevede ihtiyaç duyulan bir kaynaktır. Türkiye'de her geçen yıl nüfusun artması ve sanayileşmenin gelişmesi ile artan talep karşısında yerli fosil enerji kaynaklarının yetersiz hale geleceği öngörülmektedir [3-4]. Ayrıca çevre bilincinin artması [5], arz güvenliğinin en önemli unsuru olarak değerlendirilen dişa bağımlılı̆̆ düşürme isteği ve değişen sosyoekonomik yapı [6] fosil enerji kaynakları yerine yenilenebilir enerji kaynaklarının kullanımını gündemde tutmaktadır.

Elektrik üretim süreçlerinde hem mevcut durum analizi hem de gelecek projeksiyonları bir arada düşünülerek ülkeler tarafından uzun dönemli stratejik planlar oluşturulmaktadır. Türkiye'de bu planlar ETKB tarafindan dört y1lda bir oluşturularak kamuoyuna sunulmaktadır. Hayati öneme sahip elektrik üretim planlarında yer alan hedeflerin gerçekleşme durumları ne yazık ki süreçler tamamlandiktan sonra değerlendirilebilmektedir. Fakat bu kadar önemli planların sonuçlarının bilimsel yaklaşımlarla öngörülebilir kılınması hedeflerin tutarlılığ açısından büyük önem arz etmektedir. $\mathrm{Bu}$ çalışmada, uygulanan analitik yaklaşımla ETKB tarafından belirlenen hedeflerin tutarlığı ortaya koyulmuştur. Bu kapsamda, Türkiye'de elektrik üretiminde kullanılan enerji kaynaklarının mevcut durumu ve etkileri analiz edilerek karşılaştırmalar yapılmıştır.

Fosil enerji kaynakları yenilenebilir enerji kaynakları ile karşılaştırıldığında olumsuz çevre etkileri, kaynakların azalması ve dışa bağımlılık oranında artış gibi birçok sorunu gündeme getirmektedir. Diğer taraftan enerji ihtiyacının sürekli artması yapılacak planlamanın da yeterli miktarda, sürekli, güvenilir ve ekonomiye maksimum katkı sağlayacak şekilde yapılmasını gerektirmektedir [6]. Bu planlama dışa bağımlılı̆̆ ve çevreye olumsuz etkileri minimize edecek yenilenebilir enerji kaynaklarını kullanan, güvenlik önlemleri tam anlamıyla sağlanmış, düşük maliyetli yüksek enerji üreten nükleer enerji kaynağı kullanan [7-8] ve çevre kirliliğini minimize edecek önlemlerle yerli linyit kaynaklarını kullanan santraller ile birlikte yapılmalıdır [6].

Genel olarak güç sistemi planlanırken çevre, teknik, ekonomi ve sosyo-politik faktörler dikkate alınmaktadır [9]. Fakat bu planlama sürecinin ilk aşaması ihtiyaç duyulacak enerji miktarının doğru belirlenmesini gerektirmektedir. Bu sebeple ihtiyaç duyulacak elektrik talep tahmininin doğruluğu uzun dönemli yatırım kararlarında oldukça etkilidir [10]. Uzun dönemli yük tahminlerinde nüfus artış hızı, sanayi ve teknoloji gelişim endeksleri, kişi başına düşen ortalama yıllık gelir gibi makroekonomik faktörler kullanılmaktadır [11-14]. 
Planlama sürecinin ikinci aşaması ise ihtiyaç duyulacak elektrik enerjisini karşılayabilmek için optimal yatırım kararlarının verilmesi olarak değerlendirilebilir. $\mathrm{Bu}$ süreç dinamik bir bakış açısı gerektirmektedir. Politika oluşturucuların öngörülen ya da öngörülemeyen risk faktörlerini de bu planlamalara dâhil etmesi gerekmektedir [15].

Örneğin; yenilenebilir enerji kaynakları için güneşlenme miktarı, barajlar ve akarsulardaki doluluk oranları, rüzgâr durumu gibi faktörler oluşturulacak politikalarda değişimlere neden olabilmektedir. Bu planlar çerçevesinde her y1l Türkiye elektrik üretim karmasında değişiklikler yaşanmaktadır. Tüik'ten alınan verilere göre yıllar içinde bu enerji karmasının değişimi Şekil 1'de verilmiştir.

$\mathrm{Bu}$ çerçevede, ETKB'nin gelecek 20 yıllık projeksiyonları göz önünde bulundurularak uygulanan karar verme modeliyle hedeflerin gerçekleşme durumları incelenmiştir. Elde edilen bulgulara göre, artan enerji ihtiyacını karşılayabilmek ve dışa bağımlılığı azaltabilmek için fosil kaynak kullanımı miktar olarak bir artış gösterse de elektrik üretimindeki enerji karması içindeki oranının azalacağı öngörülmektedir. Diğer taraftan, yenilenebilir enerji kaynaklarının ise hem kullanım miktarlarının hem de enerji karması içindeki paylarının artma eğilimi göstereceği tespit edilmiştir.

\section{ENERJII YATIRIMLARINDA KARAR VERME SÜRECI}

Doğanın insana sunduğu ve günümüzde yaşam koşullarının en büyük bağımlılığı enerjidir. İnsan varlığını sürdürürken hemen her alanda enerji tüketmektedir [9]. Dolayısıyla, enerji kaynaklarının sürdürülebilirliği ile ilgili çalışmalar önemini ve güncelliğini korumaktadır.

Tüm dünyada hissedildiği gibi 1973 ve 1979 petrol krizleri [16] ile 1990 petrol fiyatı şoku [17] gelişmekte olan ülkelerde de etkisini hissettirmiştir. Türkiye de bu kriz dönemlerinden sonra alternatif enerji kaynağı arayışına girmiştir [18]. Elektrik üretim tesislerinin çeşitlendirilmesi, ham madde satın alınan ithalatçı ülkelerin çeşitlendirilmesi bu arayışın en önemli göstergeleridir [15,19].

Türkiye'de özellikle 1985 yılında yaşanan pik seviyeden sonra günümüze kadar kömür yakıtlı çalışan santrallerin enerji karması içindeki payının azaldığ1 görülmektedir (Şekil 1). Fakat yenilenebilir enerji ile ilgili yatırımların gecikmesi artan enerji ihtiyacını karşılayabilmek için gelişmekte olan çok sayıda ülke gibi Türkiye'yi de bir diğer fosil kaynak olan doğal gaz kullanımına yönlendirmiştir. 1970 yılından bu güne kadar bir değerlendirme yapılırsa, her ne kadar fosil kaynaklı elektrik üretim oranı yüksek gibi görünse de çeşitlilik anlamında giderek bir dengelenmenin yaşandığ 1 gözlemlenmektedir.

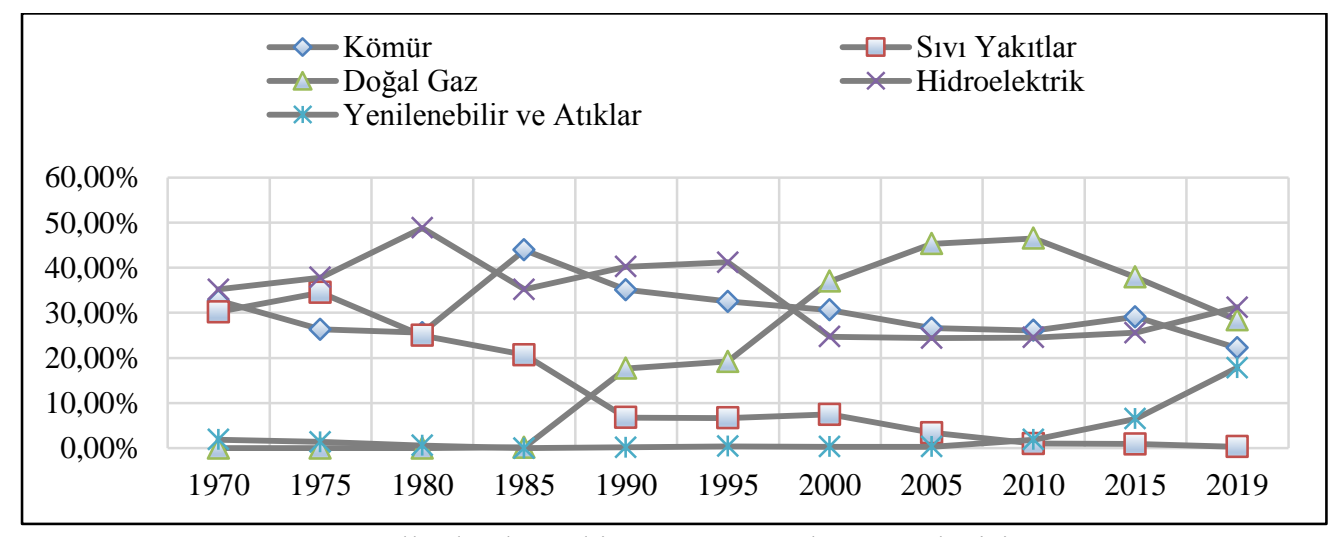

Şekil 1. Yıllar bazlı Türkiye'deki enerji karması değişim [21] 
Elektrik enerjisi üretiminde çeşitliliğin değerlendirilmesi karar vericiler için önemli bir faktördür [15]. Çeşitlilik oranı bir gösterge olarak dışa bağımlılık, tek tip enerji kaynağına bağımlılık [19] gibi konularda fikir vererek güvenilir bir elektrik arz sistemi oluşturmak noktasında karar vericilere yol göstermektedir.

Enerji üretiminde çeşitlilik, üretimde kullanılan kaynak, enerji ithal edilen ülke, taşıma güzergâhları ve dağıtım ağı olmak üzere dört temel başlıkta incelenmektedir [15,19-20]. Bu çalışmada çeşitlilik elektrik üretiminde kullanılan kaynak kapsamında incelenmektedir.

Ele alınan elektrik enerjisi ikincil enerji kaynağı olduğu için üretiminde petrol, doğal gaz, kömür, uranyum gibi fosil yakıtların yanı sıra rüzgâr, su, güneş, jeotermal gibi yenilenebilir enerji kaynakları kullanılmaktadır [22]. Burada kullanılan enerji türlerinden fosil yakıtlar sonlu ve tükenebilirken, yenilenebilir enerji kaynaklarının bu gibi kısıtları yoktur. $\mathrm{Bu}$ farklılık sebebi ile ülkeler yaptıkları stratejik planlamalarda sürekliliği koruyabilmek amacı ile yenilenebilir enerji kaynaklarına ilgi göstermektedir [5].

Elektrik üretimi ile ilgili ülkelerin farklı tutumları olmasına rağmen fosil enerji kaynakları kullanmanın çevreye olumsuz etkileri değerlendirildiğinde üretim portföyünün çeşitlendirilmesi gerekliliği ortaya çıkmaktadır $[3,19,23]$. Bilimsel çalışmalar bu durumu kanıtlar nitelikte olsa da özellikle Avrupa Birliği ülkelerindeki uygulamalar bunun aksini göstermektedir [24]. Dolayısıyla, bu çalışmada beklenen tutumdan ziyade gerçek koşulların enerji üretim portföyündeki etkileri değerlendirilmiştir.

Türkiye doğal kaynakları açısından incelendiğinde doğal gaz ve petrol kaynaklarında fakir bir ülkedir [3]. Bu sebeple ekonomik sürdürülebilirlik bağlamında mevcut linyit kaynaklarının kullanımının tamamen durdurulması mümkün görülmemektedir. Ayrıca yenilenebilir enerji kaynakları ile gerçekleştirilecek kararsız ve dalgalı elektrik üretimi bir ülkenin tüm enerji portföyünün oluşmasında bu kaynaklarının kullanımına imkân tanımamaktadır. Böylece olumsuz çevre etkileri de düşünüldüğünde, fosil yakıtlı elektrik üretim tesislerinin enerji karmasındaki paylarının azaltılması ya da başka bir ifadeyle paylarındaki artış hızının düşürülmesi bir çözüm olarak karşımıza çıkmaktadır. Bu durum karar vericileri, nükleer enerji santrali ve yenilenebilir enerji santrallerinin planlamadaki gücünü arttırmaya teşvik etmektedir.

\subsection{Yeni Yatırımların Planlanmasında Kullanılan Yöntemler}

Literatür incelendiğinde elektrik enerjisi üretiminde yeni yatırım planlarının Çok Kriterli Karar Verme Yöntemleri (ÇKKVY) ile belirlendiği görülmektedir. ÇKKVY, politika oluşturmak ve en uygun çözümü elde etmek için güvenilir ve verimli araçlardır [25]. Bu yaklaşımlar kriter ve alternatiflerin göreceli önem derecelerinin belirlenmesini sağlamaktadır [26]. Bu sayede alternatiflerin siralanmasi, aralarında en ideal seçimin belirlenmesi veya bir portföyü oluşturan karmanın belirlenmesi gibi amaçlarla kullanılmaktadır.

Çok kriterli karar vermenin görece kısa bir geçmişi vardır. Modern çok kriterli karar verme yöntemlerinin temellerinin atıldığ 1950 'lerden bu yana, yeni çok kriterli karar verme modelleri ve tekniklerinin geliştirilmesine odaklanılmıştır [27]. Çizelge 1 'de en çok kullanılan ÇKKVY listelenmiştir.

Çizelge 1. Çok kriterli karar verme yöntemleri

\begin{tabular}{|l|l|}
\hline Yöntem & Yazarlar ve Kaynak No \\
\hline AHP-ANP & Saaty [30-31] \\
\hline DEMATEL & Gabus Fontela [32] \\
\hline ELECTRE & Roy [33] \\
\hline MAUT-MAVT & Fisburn [34] \\
\hline PROMETHEE & Brans [35] \\
\hline SAW & Churchman ve Ackoff [36] \\
\hline TOPSIS & Yoon [37] \\
\hline ARAS & Zavadskas ve Turskis [38] \\
\hline COPRAS & Zavadskas ve Kaklauskas [39] \\
\hline MOORA & Brauers ve Zavadskas [40] \\
\hline SWARA & Zavadskas vd. [41] \\
\hline WASPAS & Zavadskas vd. [42] \\
\hline
\end{tabular}


Enerji planlanmasında teknolojinin sürdürülebilirliği çeşitli yöntem ve kriter kombinasyonları ile değerlendirilmektedir [28].

Bazı çalışmalar geleneksel enerji üretim teknolojilerini yeni teknolojilerle karşılaştırmaya veya çeşitli yenilenebilir enerji teknolojilerini yaşam döngüsü açısından karşılaştırmaya odaklanmaktadır [26,29]. Elektrik santrallerinin değerlendirilmesinde kullanılan kriterler, aynı zamanda yapılacak yeni yatırımların planlanmasında da kullanılabilmektedir.

\subsection{Yeni Yatırımların Kullanılan Kriterler}

Elektrik üretim sistemlerinin değerlendirilmesi amacıyla yapılan çalışmalarda çok sayıda kriter kullanılmaktadır [22,43]. Bu kriterlerin bir özeti Çizelge 2'de verilmiştir.

Çizelge 2. Elektrik üretim sistemleri değerlendirilmesinde kullanılan kriterler

\begin{tabular}{|c|c|}
\hline KRİTER & ALT KRITTER \\
\hline \multirow{4}{*}{ Teknik } & Y1ll1k Üretim \\
\hline & Birincil Enerji Oranı \\
\hline & Kapasite Faktörü \\
\hline & Kurulu Güç \\
\hline \multirow{2}{*}{ Sosyo-politik } & Sosyal Kabul Edilebilirlik \\
\hline & Yeni İş Oluşturma \\
\hline \multirow{7}{*}{ Çevre } & $\mathrm{CO}_{2}$ Emisyonu \\
\hline & CO Emisyonu \\
\hline & $\mathrm{CH}_{4}$ Emisyonu \\
\hline & SO Emisyonu \\
\hline & $\mathrm{N}_{2} \mathrm{O}$ Emisyonu \\
\hline & $\mathrm{NO}_{\mathrm{x}}$ Emisyonu \\
\hline & Arazi Kullanımı \\
\hline \multirow{4}{*}{ Ekonomik } & Yatırım Maliyeti \\
\hline & İşletme ve Bakım Maliyeti \\
\hline & Yakıt Maliyetleri \\
\hline & Geri Ödeme Süresi \\
\hline
\end{tabular}

Çizelge 2'de Wang'ın ortaya koyduğu kriterler, genel değerlendirme kriterleri olarak kabul görmüş olmasına rağmen çok sayıda araştırmada problemin odağına göre kullanılan kriterlerde farklılıklar görülmektedir $[9,43]$. Yang ve arkadaşlarının yaptıkları çalışmada teknoloji, ekonomi, çevre ve sosyal indeks olmak üzere Çizelge 2'de verilen kriterlere benzer bir yaklaşım sergilenmiştir [44]. Fakat alt kriterler incelendiğinde bu çalışmada sosyal indeksin daha baskın olduğu görülmektedir. Ayrıca güvenlik alt kriteri çoğunlukla teknik kriterinin altında yer alırken, Yang ve arkadaşları bu kriteri sosyal bir kriter olarak ele almışlardır [44]. Benzer şekilde Özcan ve Erol'un [45] yaptıkları çalışmada sosyal kabul kriterinin araştırmanın odağında olduğu görülmektedir. Alanne ve arkadaşları ise yaptıkları çalışmada verilen kriterlere ek olarak teknoloji kullanımı ile ilgili yeni bir kriter eklemişlerdir [46].

$\mathrm{Bu}$ çalışma kapsamında kullanılan kriterler ve alt kriterler ilgili elektrik santral tipi karşılaştırmaları ile birlikte bir sonraki bölümde verilmiştir.

\section{YÖNTEM}

Bu çalışmada elektrik santralleri ile ilgili yapılacak planlamada Türkiye Cumhuriyeti Enerji ve Tabii Kaynaklar Bakanlığı'nın halka açık olarak yayınladığı elektrik enerjisi talep projeksiyonları verileri kullanılmıştır (Çizelge 3) [47].

Çizelge 3. Türkiye elektrik talep tahminleri (TWh)

\begin{tabular}{|c|c|c|c|}
\hline YIL & Düşük & Baz & Yüksek \\
\hline $\mathbf{2 0 2 0}$ & 327,30 & 329,60 & 332,10 \\
\hline $\mathbf{2 0 2 1}$ & 340,50 & 344,40 & 348,70 \\
\hline $\mathbf{2 0 2 2}$ & 353,20 & 359,60 & 366,40 \\
\hline $\mathbf{2 0 2 3}$ & 366,80 & 375,80 & 385,20 \\
\hline $\mathbf{2 0 2 4}$ & 380,40 & 392,10 & 404,30 \\
\hline $\mathbf{2 0 2 5}$ & 392,60 & 406,90 & 422,30 \\
\hline $\mathbf{2 0 2 6}$ & 404,60 & 421,80 & 440,70 \\
\hline $\mathbf{2 0 2 7}$ & 416,60 & 436,60 & 458,90 \\
\hline $\mathbf{2 0 2 8}$ & 428,80 & 451,70 & 477,60 \\
\hline $\mathbf{2 0 2 9}$ & 441,00 & 466,80 & 496,60 \\
\hline $\mathbf{2 0 3 0}$ & 453,00 & 481,70 & 515,40 \\
\hline $\mathbf{2 0 3 1}$ & 464,60 & 496,70 & 534,00 \\
\hline $\mathbf{2 0 3 2}$ & 476,30 & 511,60 & 552,90 \\
\hline $\mathbf{2 0 3 3}$ & 487,80 & 526,40 & 571,60 \\
\hline $\mathbf{2 0 3 4}$ & 499,30 & 541,00 & 590,20 \\
\hline $\mathbf{2 0 3 5}$ & 510,80 & 555,70 & 608,50 \\
\hline $\mathbf{2 0 3 6}$ & 522,70 & 570,80 & 627,00 \\
\hline $\mathbf{2 0 3 7}$ & 534,00 & 585,30 & 644,90 \\
\hline $\mathbf{2 0 3 8}$ & 545,10 & 599,40 & 662,50 \\
\hline $\mathbf{2 0 3 9}$ & 556,30 & 613,40 & 679,90 \\
\hline
\end{tabular}


Talep tahminleri doğrultusunda hangi birincil enerji kaynağından ne oranda bir yatırım karması oluşturulacağına karar verilecektir. Karar problemi için AHS yöntemi kullanılmıştır. Fakat öncesinde AHS yönteminin öznelliğini azaltmak ve enerji karmasını arz güvenliği yaklaşımı ile şekillendirmek için tasarlanmış veri önişleme adımları uygulanmıştır. $\mathrm{Bu}$ aşamada verilerin 13 kriter için sahip oldukları değerler kendi içinde değerlendirilerek ödül ve ceza puanları verilmiştir. $\mathrm{Bu}$ puanların oluşmasında kullanılan yöntem 3.2 başlığı altında detaylandırılmıştır.

\subsection{Analitik Hiyerarşi Süreci (AHS)}

AHS, karmaşık kararları bir dizi ikili karşılaştırmaya indirgeyerek ve ardından sonuçları sentezleyerek, karmaşık bir sorunun hiyerarşiler sistemine bölünmesine izin veren çok kriterli bir karar verme yöntemidir [48]. AHS, karar vericinin kriterleri ikili karşılaştırmasına göre her değerlendirme kriteri için bir ağırlık oluşturur. Ağırlık ne kadar yüksek olursa, karşılık gelen kriter de o kadar önemlidir ve analiz edilen kriterler arasında bir öncelik siralaması oluşturulması mümkündür [49].

AHS yönteminin algoritmik yapısı aşağıdaki gibi özetlenebilir [31].

- Problemin tanımlanması

- Kriterlerin ve alternatiflerin belirlenmesi

- Hiyerarşik karar diyagramının belirlenmesi

- Veri matrislerinin oluşturulmasi

- Ağırlıkların hesaplanması

- Karşılaştırmaların yapılması

- Tutarlılık kontrolünün yapılması

- Kararın verilmesi

Kriterler ve alternatiflerin önem düzeyleri belirlenirken Saaty'nin geliştirdiği ölçek kullanılmaktadır [31]. Saaty önem düzeyi ölçeği Çizelge 4'de verilmiştir.

Çizelge 4. AHS Önem düzeyleri çizelgesi

\begin{tabular}{|c|l|}
\hline Puan & Değer \\
\hline $\mathbf{1}$ & Eşit önem düzeyi \\
\hline $\mathbf{3}$ & Kı̈men önemli \\
\hline $\mathbf{5}$ & Önemli \\
\hline $\mathbf{7}$ & Çok önemli \\
\hline $\mathbf{9}$ & Aşırı önemli \\
\hline $\mathbf{2 , 4 , 6 , 8}$ & Ara değerler \\
\hline
\end{tabular}

Çizelge 4'de belirtilen önem düzeyleri arasında göreceli belirsizlikler olduğunda ara değer olarak verilen 2, 4, 6 ve 8 değerleri kullanılmaktadır.

Buradan elde edilen değerlendirmelere dayanarak karşılaştırma matrisi Eşitlik 1'deki gibi oluşturulur.

$\mathrm{A}_{\mathrm{nxn}}=\left[\mathrm{a}_{\mathrm{ij}}\right] ; \quad \mathrm{i}, \mathrm{j} \in\{1,2, \ldots, \mathrm{n}\}$

Karş1laştırma matrisinde $\mathrm{i}=\mathrm{j}$ olduğunda hücreler 1 değerini alırken, diğer hücrelerde belirlenen önem düzeylerine göre puanlamalar yapılır. Ayrıca simetrik hücreler için Eşitlik 2'deki dönüşüm uygulanmaktadır.

$a_{j i}=\frac{1}{a_{i j}}$

Karşılaştırma matrisleri her kriter için ayrı ayrı yapılarak hesaplamalar yapılmaktadir. Her bir karşılaştırma matrisi Eşitlik 3 ile normalize edilerek sütun değerleri toplamının 1 olması sağlanır.

$$
* \mathrm{a}_{\mathrm{ij}}=\frac{\mathrm{a}_{\mathrm{ij}}}{\sum \mathrm{a}_{\mathrm{j}}}
$$

Normalize edilen kriter matrislerinin Eşitlik 4 yardımı ile satır ortalamaları alınarak öncelik (ağırlık) matrisi elde edilir.

$\mathrm{w}_{\mathrm{i}}=\frac{\sum * \mathrm{a}_{\mathrm{ij}}}{\mathrm{n}}$ 
Son adım olarak Eşitlik 8 ve Çizelge 5'de verilen Rastgele Gösterge (RI) değerleri ile elde edilen sonuçların tutarlılıkları (CR) hesaplanır. Burada CI değerlerinin hesaplanması için sırası ile Eşitlik 5, 6 ve 7 uygulanır.

$$
\begin{aligned}
& \operatorname{det}(\mathrm{A}-\lambda \mathrm{I})=0 \\
& \lambda_{\max }=\max \lambda_{\mathrm{i}} \\
& \mathrm{CI}=\frac{\lambda_{\max }-\mathrm{n}}{\mathrm{n}-1} \\
& \mathrm{CR}=\frac{\mathrm{CI}}{\mathrm{RI}}
\end{aligned}
$$

Çizelge 5. Rastgele gösterge değerleri

\begin{tabular}{|c|c|c|c|c|}
\hline $\mathbf{n}$ & $\mathbf{R I}$ & & $\mathbf{n}$ & $\mathbf{R I}$ \\
\hline 1 & 0,00 & & 6 & 1,24 \\
\hline 2 & 0,00 & & 7 & 1,32 \\
\hline 3 & 0,58 & & 8 & 1,41 \\
\hline 4 & 0,90 & & 9 & 1,45 \\
\hline 5 & 1,12 & & 10 & 1,49 \\
\hline
\end{tabular}

Hesaplanan CR değerinin 0'a olan yakınlığı karar vericinin yaptığı karşılaştırmaların tutarlılı̆̆ının arttığını göstermektedir [31].

AHS yönteminde asıl sorun kriter ve alternatiflerin ağırlıklarının belirlenmesi sürecinde, insanların öznel yargılarının etkisidir [50]. Sonuç olarak, karar matrislerinin oluşturulması bazı belirsiz faktörlerden etkilenir ve tutarlılığı sağlamak zordur [51]. Bu çalışmada AHS yönteminin doğasında yer alan öznellik tutumu azaltabilmek için bir dizi önişlem uygulaması önerilmektedir.

\subsection{Veri Önişleme}

Literatürde birçok veri önişleme yöntemi bulunmaktadır. Veri ön işlemenin genel amacı uygulanacak olan yönteme verilerin en iyi girdiyi oluşturmasıdır [52]. Bu çalışmada uygulanacak veri önişleme tekniği ise AHS yönteminde göze çarpan öznelliği azaltacak bir yaklaşım olarak tasarlanmıştır.

$\mu \boldsymbol{\mu}: i$. Alt kriterin ortalama değeri oi:i. Alt kriterin standart sapması

$\gamma$. Esneklik katsayısı

olmak üzere puanlama aralığı (r) Eşitlik 9'da verilmiştir,

$\mathrm{r}_{\mathrm{i}}: \frac{\sigma_{\mathrm{i}}}{\gamma}$

Eşitlik 10 yardımı ile her kriter kendi içinde puanlanmaktadır.

$p_{i}\left(x_{i}\right)=\left\{\begin{array}{c}0, \quad v^{2} x_{i} \in\left(\mu_{i}-\frac{r_{i}}{2}, \mu_{i}+\frac{r_{i}}{2}\right) \\ t, \quad \operatorname{vex}_{i} \in\left(\mu_{i}-\frac{t_{i}}{2}, \mu_{i}+\frac{(t+2) \cdot r_{i}}{2}\right)\end{array}\right.$

Burada alt kriterlerin aldığı ödül puanları pozitif, ceza puanları negatif olarak elde edilmektedir. Her bir kriterin puanı hesaplanırken alt kriterlerinin ödül ve ceza puanlarının ortalaması alınır. Son olarak elde edilen kriter puanları min-max yöntemi ile standardize edilir.

\section{3. Çalışmada Kullanılan Kriter Değerleri ve Puanları}

Çalışmada kullanılan her bir alternatifin kriterlerinin aldığı değerler ve uygulanan veri önişleme sonucunda elde edilen puanlamaları aşağıda verilmiştir.

\subsubsection{Kurulu Güç (K1)}

Bu kriter Türkiye'de 2019 y1lı sonunda oluşmuş kurulu güçleri (Çizelge 6) göstermektedir [53].

Çizelge 6. Kurulu güç

\begin{tabular}{|l|c|c|c|}
\hline Santral Tipi & MW & Yüzde & Puan \\
\hline Nükleer & 0,00 & 0,00 & - \\
\hline Kömür & 20321,3 & 22,4 & 6 \\
\hline Doğal gaz & 25945,9 & 28,6 & 11 \\
\hline Hidroelektrik & 28486,1 & 31,4 & 13 \\
\hline Rüzgar & 7348,3 & 8,1 & -5 \\
\hline Güneş & 5624,6 & 6,2 & -6 \\
\hline Jeotermal & 1451,5 & 1,6 & -10 \\
\hline Diğer (Atık vb.) & 1542,2 & 1,7 & -10 \\
\hline TOPLAM & 90720 & 100 & - \\
\hline
\end{tabular}




\subsubsection{Yıllık Üretim Miktarı (K2)}

Bu kriter 2019 yılının tamamında birincil enerji kaynaklarına göre üretilen elektrik enerjisini (Çizelge 7) göstermektedir [54].

Çizelge 7. Y1llık üretim

\begin{tabular}{|l|c|c|c|}
\hline Santral Tipi & GW & Yüzde & Puan \\
\hline Nükleer & 0,00 & 0,00 & - \\
\hline Kömür & 113117,82 & 37,18 & 16 \\
\hline Doğal gaz & 56702,69 & 18,64 & 3 \\
\hline Hidroelektrik & 88886,24 & 29,21 & 10 \\
\hline Rüzgar & 29672,90 & 9,75 & -3 \\
\hline Güneş & 240,90 & 0,08 & -10 \\
\hline Jeotermal & 11363,20 & 3,73 & -7 \\
\hline Diğer (Atık vb.) & 5257,63 & 1,4 & -9 \\
\hline TOPLAM & 305241,40 & 100 & - \\
\hline
\end{tabular}

\subsubsection{Kapasite Faktörü (K3)}

Çizelge 8. Ortalama kapasite faktörü

\begin{tabular}{|l|c|c|}
\hline Santral Tipi & KF & Puan \\
\hline *Nükleer & 0,9000 & 12 \\
\hline Kömür & 0,8354 & 10 \\
\hline Doğal gaz & 0,2495 & -9 \\
\hline Hidroelektrik & 0,4562 & -2 \\
\hline Rüzgar & 0,2610 & -9 \\
\hline Güneş & 0,2049 & -11 \\
\hline Jeotermal & 0,7937 & 9 \\
\hline Diğer (Atık vb.) & 0,6892 & 5 \\
\hline
\end{tabular}

*Türkiye'de kurulu nükleer santral olmadığı için EIA'dan hesaplanan ortalama değer verilmiştir.

Kapasite faktörü bir santralin bir yılda ürettiği gücün yine bir yılda üretilebilecek maksimum güç değerine oranı Eşitlik 11 kullanılarak hesaplanır [55].

$\mathrm{KF}=\frac{\text { Üretilen toplam güç }}{\text { Kurulu güç (yıllık) }}$

\subsubsection{Yatırım Maliyetleri (K4)}

Yatırım maliyeti birçok maliyet kaleminin toplamından oluşmaktadır. $\mathrm{Bu}$ çalışmada kullanılan veriler ekipman, malzeme, inşaat, işçilik, vinçler, mühendislik hizmetleri, inşaat yönetimi, devreye alma ve işletmeye alma maliyetlerinin toplamını (Çizelge 9) içermektedir [56,57].

Çizelge 9. Yatırım maliyetleri

\begin{tabular}{|l|c|c|}
\hline Santral Tipi & $\mathbf{\$ / k W h}$ & Puan \\
\hline Nükleer & 6041 & -18 \\
\hline Kömür & 3676 & -5 \\
\hline Doğal gaz & 978 & 11 \\
\hline Hidroelektrik & 5316 & -16 \\
\hline Rüzgar & 1265 & 10 \\
\hline Güneş & 1755 & 6 \\
\hline Jeotermal & 2521 & 2 \\
\hline Diğer (Atık vb.) & 4097 & -8 \\
\hline
\end{tabular}

\subsection{5. İşletme ve Bakım Maliyetleri (K5)}

İşletme ve bakım maliyetleri de birçok maliyet kaleminin toplamından oluşmaktadır. Araştırmada kullanılan veriler sabit işletme, bakım, malzeme, sözleşme bedelleri, geçici işçi, su, kimyasallar ve sarf malzeme maliyetlerinin toplamını (Çizelge 10) içermektedir. $\mathrm{Bu}$ maliyetlere vergi ve sigorta maliyetleri dâhil edilmemiştir [57].

Çizelge 10. İşletme ve bakım maliyetleri

\begin{tabular}{|l|c|c|}
\hline Santral Tipi & $\mathbf{\$ / k W h}$ & Puan \\
\hline Nükleer & 121,64 & -13 \\
\hline Kömür & 40,58 & 3 \\
\hline Doğal gaz & 13,17 & 8 \\
\hline Hidroelektrik & 29,86 & 5 \\
\hline Rüzgar & 26,34 & 6 \\
\hline Güneş & 15,25 & 8 \\
\hline Jeotermal & 128,54 & -15 \\
\hline Diğer (Atık vb.) & 125,72 & -14 \\
\hline
\end{tabular}

\subsubsection{Yakıt Maliyetleri (K6)}

Çizelge 11. Yakıt maliyetleri

\begin{tabular}{|l|c|c|}
\hline Santral Tipi & \$ cent/kWh (yıl) & Puan \\
\hline Nükleer & 0,76 & 3 \\
\hline Kömür & 4 & -8 \\
\hline Doğal gaz & 8 & -22 \\
\hline Hidroelektrik & 0 & 5 \\
\hline Rüzgar & 0 & 5 \\
\hline Güneş & 0 & 5 \\
\hline Jeotermal & 0 & 5 \\
\hline Diğer (Atık vb.) & 0 & 5 \\
\hline
\end{tabular}


Bu kriterde üretim süreçlerinde kullanılan birincil enerji kaynağının $\mathrm{kW}$ başına ortalama cent değerleri (Çizelge 11) verilmiştir [57].

\subsubsection{Geri Ödeme Süresi (K7)}

$\mathrm{Bu}$ kriter önceki çalışmalarda emisyon değerlerine karşılık alınan ödül sistemine göre [58] ve finansal olarak yatırım bedelinin karşılanma süresi olarak iki farklı şekilde değerlendirilmiştir. $\mathrm{Bu}$ araştırmada finansal bir değerlendirme kullanılmıştır (Çizelge 12).

Çizelge 12. Geri ödeme süresi

\begin{tabular}{|l|c|c|}
\hline Santral Tipi & Ortalama (yıl) & Puan \\
\hline Nükleer & 9,2 & 6 \\
\hline Kömür & 10 & 3 \\
\hline Doğal gaz & 9,72 & 4 \\
\hline Hidroelektrik & 14,65 & -11 \\
\hline Rüzgar & 6,94 & 13 \\
\hline Güneş & 8,65 & 7 \\
\hline Jeotermal & 16 & -15 \\
\hline Diğer (Atık vb.) & 11,5 & -1 \\
\hline
\end{tabular}

Geri ödeme süresi her kaynak için birçok maliyet kalemi hesaplanarak yapıldığından veriler ortalama değerler olarak alınmıştır [59-64]. Verilen değerler ülkelere göre farklılık gösterebilmektedir.

\subsubsection{Emisyonlar (K8-K9-K10-K11)}

Önceden yapılan çalışmalarda bu kriterde genellikle tüm sera gazlarını temsilen karbon piyasasındaki ödül ve ceza puanları kullanılmıştır [21]. Bu çalışmada ise santral tiplerinin inşaat ve işletme aşamasında doğaya saldıkları $\mathrm{CO}_{2}, \mathrm{CH}_{4}$, $\mathrm{NO}_{x}$ ve $\mathrm{SO}_{2}$ gazların ortalama değerleri (Çizelge 13) kullanılmıştır [57].

Çizelge 13. Emisyonlar (g/kWh)

\begin{tabular}{|l|c|c|c|c|}
\hline Santral Tipi & $\mathbf{C O}_{\mathbf{2}}$ & $\mathbf{C H}_{\mathbf{4}}$ & $\mathbf{N O}_{\mathbf{x}}$ & $\mathbf{S O}_{\mathbf{2}}$ \\
\hline Nükleer & 17 & 0 & 0,047 & 0,072 \\
\hline Kömür & 838 & 4,716 & 0,696 & 0,351 \\
\hline Doğal gaz & 386 & 1,076 & 0,351 & 0,125 \\
\hline Hidroelektrik & 32 & 0,135 & 0,056 & 0,055 \\
\hline Rüzgâr & 38 & 0,169 & 0,055 & 0,071 \\
\hline Güneş & 319 & 0,883 & 0,408 & 0,494 \\
\hline Jeotermal & 21 & 0,059 & 0 & 0 \\
\hline Diğer (Atık vb.) & 0 & 0 & 0,35 & 0,087 \\
\hline
\end{tabular}

Çizelge 14. Emisyon puanları

\begin{tabular}{|l|c|c|c|c|}
\hline Santral Tipi & $\mathbf{C O}_{\mathbf{2}}$ & $\mathbf{C H}_{\mathbf{4}}$ & $\mathbf{N O}_{\mathbf{x}}$ & $\mathbf{S O}_{\mathbf{2}}$ \\
\hline Nükleer & 6 & 5 & 8 & 5 \\
\hline Kömür & -21 & -24 & -18 & -11 \\
\hline Doğal gaz & -6 & -1 & -4 & 2 \\
\hline Hidroelektrik & 6 & 4 & 8 & 6 \\
\hline Rüzgar & 6 & 3 & 7 & 5 \\
\hline Güneş & -4 & 0 & -10 & -20 \\
\hline Jeotermal & 6 & 5 & 10 & 9 \\
\hline Diğer (Atık vb.) & 7 & 5 & -4 & 4 \\
\hline
\end{tabular}

Çizelge 14 emisyon değerlerine uygulanan veri ön işlemeden sonra oluşan puanlamayı göstermektedir.

\subsubsection{Arazi Kullanımı (K12)}

Elektrik üretim santralleri belirli büyüklüklerde arazi üzerine kurulurlar. Büyüklük ölçüsü santralin kapasitesine bağlı olarak değişmektedir. $\mathrm{Bu}$ sebeple santral tiplerinin kuruldukları alan 1000 MW eş değeri (Çizelge 15) olarak kabul edilmiştir.

Çizelge 15. Arazi kullanımı

\begin{tabular}{|l|c|c|}
\hline Santral Tipi & $\mathbf{K m}^{\mathbf{2}} / \mathbf{1 0 0 0} \mathbf{~ M W}$ & Puan \\
\hline Nükleer & 2,5 & 8 \\
\hline Kömür & 2,5 & 8 \\
\hline Doğal gaz & 2,5 & 8 \\
\hline Hidroelektrik & 750 & 0 \\
\hline Rüzgar & 100 & 7 \\
\hline Güneş & 35 & 8 \\
\hline Jeotermal & 18 & 8 \\
\hline Diğer (Atık vb.) & 5000 & -49 \\
\hline
\end{tabular}

\subsubsection{0. İş Oluşturma (K13)}

Elektrik üretim santralleri yaşam döngüsü boyunca inşaat işletme ve hizmet alma aşamalarında birçok kişiye iş imkânı sağlamaktadır [21,65]

$\mathrm{Bu}$ kriter enerji tedarik sistemlerinin istihdam potansiyeli olarak değerlendirilmiş ve ortalama çalışan sayıları Çizelge 16'da verilmiştir. 
Çizelge 16. İș oluş̧urma

\begin{tabular}{|l|c|c|}
\hline Santral Tipi & Kişi / MW & Puan \\
\hline Nükleer & 0,833333 & 16 \\
\hline Kömür & 0,537634 & 3 \\
\hline Doğal gaz & 0,394737 & -3 \\
\hline Hidroelektrik & 0,740741 & 12 \\
\hline Rüzgar & 0,30303 & -7 \\
\hline Güneş & 0,447412 & -1 \\
\hline Jeotermal & 0,155556 & -14 \\
\hline Diğer (Atık vb.) & 0,354167 & -5 \\
\hline
\end{tabular}

\section{BULGULAR}

Çalışmada yapılan veri önişleme süreci, ortalamalardan sapmaya dayalı ödül ve ceza puanlarının verilmesi esasında uygulandığı için model her geçen yıl enerji karmasını daha dengeli bir hale getirmeye amaçlamaktadır.

Enerji santrallerinin değerlendirilmesi amacıyla dört ana kriter altında 13 alt kriter $(\mathrm{K} 1, \ldots, \mathrm{K} 13)$ kullanılmıştır. $\mathrm{Bu}$ kriterlerden $\mathrm{K} 1$ ve K2'nin değerleri her yıl yeniden oluşturulan yeni enerji karmasından dolayı değişim göstermektedir. Diğer kriterlerin değerleri dolar cinsinden veya ortalama olarak verildiği için değişmeyeceği varsayılmıştır. $\mathrm{Bu}$ sebeple veri önişleme adımları her yıl eklenecek yeni yatırım karması için tekrarlanarak iteratif bir süreç ortaya koymaktadır. Böylece bu iteratif süreç enerji karmasını dengelenmesi noktasında bir baskı oluşturmaktadır. Bu sebeple, bu araştırmada enerji karmasının dengelenmesi sağlanarak arz güvenliğine katkı sağlayacak bir planlama önerilmektedir.

Çalışmada kullanılan ana kriterlerin kendi aralarında karşılaştırılmasında Türkiye Cumhuriyeti Enerji ve Tabii Kaynaklar Bakanlığı'nın 2019-2023 Stratejik Plan ve Performans Göstergeleri baz alınmıştır. Böylece dışarıdan alınan ikili karşılaştırmalardan uzaklaşarak öznellik vurgusu zayıflatılmıştır [66]. Türkiye'de enerji sistemlerinde karar verici ve politika yapıcı Türkiye Cumhuriyeti Enerji ve Tabii Kaynaklar Bakanlığı olduğundan dolayı bu yaklaşım daha gerçekçi sonuçları ortaya çıkaracaktır.
$\mathrm{Bu}$ yaklaşımda Türkiye Cumhuriyeti Enerji ve Tabii Kaynaklar Bakanlığı'nın yayımladığı Stratejik Plan ve Performans Göstergeleri Çizelge 17'de verilen hedefleri göstermektedir [66]. Burada yer alan hedefler çalışmanın hangi kriteri ya da kriterleri ile ilgiliyse bu kriterlerin görece üstünlüklerini artırmıştır. Böylece klasik yaklaşımda uzman görüşlerine dayanan puanlama sistemi bu çalışmada Türkiye Cumhuriyeti Enerji ve Tabii Kaynaklar Bakanlığı'nın yazılı olarak sunduğu amaçlar ile çözümlenmiştir.

Çizelge 17'de elde edilen toplam puanlar kendi aralarında ikişer ikişer oranlanarak AHS karşılaştırma matrisi elde edilmiştir (Çizelge 18).

Çizelge 17. Türkiye Cumhuriyeti Enerji ve Tabii Kaynaklar Bakanlığı 2019-2023 stratejik planları

\begin{tabular}{|l|c|c|c|c|}
\hline & T & E & Ç & S \\
\hline $\begin{array}{l}\text { Sürdürülebilir enerji arz } \\
\text { güvenliği sağlamak }\end{array}$ & 7 & 2 & 5 & 3 \\
\hline $\begin{array}{l}\text { Enerji verimliliğini } \\
\text { önceliklendirmek ve } \\
\text { artırmak }\end{array}$ & 5 & 5 & 3 & 6 \\
\hline $\begin{array}{l}\text { Kurumsal ve sektörel } \\
\text { kapasiteyi güçlendirmek }\end{array}$ & 2 & 0 & 0 & 4 \\
\hline $\begin{array}{l}\text { Enerji ve tabii } \\
\text { kaynaklarda bölgesel ve } \\
\text { küresel etkinliği artırmak }\end{array}$ & 1 & 2 & 0 & 0 \\
\hline $\begin{array}{l}\text { Enerji ve tabii kaynaklar } \\
\text { alanında teknoloji } \\
\text { geliştirme ve } \\
\text { yerlileştirme }\end{array}$ & 4 & 1 & 0 & 3 \\
\hline $\begin{array}{l}\text { Piyasalarda } \\
\text { öngörülebilirliği artırmak }\end{array}$ & 2 & 2 & 0 & 2 \\
\hline $\begin{array}{l}\text { Sürdürülebilir madencilik } \\
\text { ile üretim kapasitesini } \\
\text { artırmak }\end{array}$ & 3 & 4 & 0 & 3 \\
\hline TOPLAM & 24 & 16 & 8 & 21 \\
\hline
\end{tabular}

Çizelge 18. AHS karşılaştırma matrisi

\begin{tabular}{|c|c|c|c|c|}
\hline & $\mathbf{T}$ & $\mathbf{E}$ & $\mathbf{C}$ & $\mathbf{S}$ \\
\hline $\mathbf{T}$ & 1,000 & 1,500 & 3,000 & 1,143 \\
\hline $\mathbf{E}$ & 0,667 & 1,000 & 2,000 & 0,762 \\
\hline $\mathbf{C}$ & 0,333 & 0,500 & 1,000 & 0,381 \\
\hline $\mathbf{S}$ & 0,875 & 1,313 & 2,625 & 1,000 \\
\hline
\end{tabular}


Çizelge 18'den elde edilen değerlere AHS metodolojisi uygulanarak Çizelge 19'de ki ağırlıklar hesaplanmıştır.

Çizelge 19. AHS faktör ağırlıkları

\begin{tabular}{|c|c|c|c|c|}
\hline & $\mathbf{T}$ & $\mathbf{E}$ & $\mathbf{C}$ & $\mathbf{S}$ \\
\hline $\mathbf{w}$ & 0,3478 & 0,1159 & 0,2319 & 0,3044 \\
\hline
\end{tabular}

Çalışmada tutarlılık ölçütü $\mathrm{CR}=1,1 * 10^{-8}$ elde edilmiştir. Değerin sıfıra çok yakın olması Türkiye Cumhuriyeti Enerji ve Tabii Kaynaklar Bakanlığı'nın stratejik hedeflerinden elde edilen karşılaştırma matrisinin tutarlı olduğuna işaret etmektedir.

Diğer taraftan alt kriterlerde de öznelliği zayıflatabilmek için sahip oldukları değerlere göre ikili karşılaştırmalarını sağlayacak bir veri önişleme daha uygulanmıştır. Burada uygulanan veri önişleme süreci Başlık 3.2'de anlatılan metodoloji yardımıyla yapılmıştır. Son olarak veri önişleme adımları ile elde edilen ödül ve ceza puanları Eşitlik 12'de belirtilen min-max normalizasyonu uygulanarak Çizelge 20'deki veri önişleme puan matrisi elde edilmiştir.

$\mathrm{p}_{\mathrm{j}}{ }^{\prime}=\frac{\mathrm{p}_{\mathrm{j}}-\min \left(\mathrm{p}_{\mathrm{j}}\right)}{\operatorname{maks}\left(\mathrm{p}_{\mathrm{j}}\right)-\min \left(\mathrm{p}_{\mathrm{j}}\right)}$

Çizelge 20. 2019 yılı veri önişleme puan matrisi

\begin{tabular}{|l|c|c|c|c|}
\hline Santral Tipi & T & E & Ç & S \\
\hline Kömür & 1,0000 & 0,2807 & 0,0000 & 0,6538 \\
\hline Doğal gaz & 0,5424 & 0,4211 & 0,6250 & 0,4231 \\
\hline Hidroelektrik & 0,8136 & 0,1053 & 0,8654 & 1,0000 \\
\hline Rüzgâr & 0,1695 & 1,0000 & 0,9038 & 0,2692 \\
\hline Güneş & 0,0000 & 0,8596 & 0,3846 & 0,5000 \\
\hline Jeotermal & 0,3220 & 0,0000 & 1,0000 & 0,0000 \\
\hline Diğer(Atık vb) & 0,2203 & 0,0877 & 0,2788 & 0,3462 \\
\hline
\end{tabular}

Çizelge 18 stratejik planlara göre hesaplandığı için sabit kalırken Çizelge 20'de yer alan değerler her yıl sonu hesaplamasında güncellenmektedir.

AHS ağırlıkları ile veri önişleme puan matrisi çarpılarak oluşturulacak yatırım portföyünün oranları belirlenmiş Çizelge 21 'de verilmiştir.
Çizelge 21. 2020 y1lı planlaması ve enerji karmasına eklenecek güç miktarı

\begin{tabular}{|l|c|c|c|c|}
\hline Santral Tipi & $\begin{array}{c}\text { S1 } \\
(\mathbf{G W})\end{array}$ & $\begin{array}{c}\text { S2 } \\
(\mathbf{G W})\end{array}$ & $\begin{array}{c}\text { S3 } \\
(\mathbf{G W})\end{array}$ & \% \\
\hline Nükleer & - & - & - & - \\
\hline Kömür & 3,80 & 4,20 & 4,63 & 17,09 \\
\hline Doğal gaz & 3,35 & 3,70 & 4,08 & 15,06 \\
\hline Hidroelektrik & 5,24 & 5,79 & 6,39 & 23,58 \\
\hline Rüzgâr & 3,05 & 3,37 & 3,72 & 13,73 \\
\hline Güneş & 2,24 & 2,47 & 2,72 & 10,05 \\
\hline Jeotermal & 2,25 & 2,49 & 2,74 & 10,12 \\
\hline Diğer (Atık vb) & 1,68 & 1,86 & 2,05 & 7,57 \\
\hline TOPLAM & 21,62 & 23,87 & 26,32 & 100 \\
\hline
\end{tabular}

Türkiye Cumhuriyeti Enerji ve Tabii Kaynaklar Bakanlığı'nın 2020 yılı için düşük (S1), baz (S2) ve yüksek (S3) olmak üzere üç farklı senaryoda yaptığı elektrik tüketim tahminleri doğrultusunda kapasitesi arttırılacak veya yeni yatırım yapılacak enerji santral güç dağılımı Çizelge 21'de verilmiştir.

Çizelge 22. 2020-2023 planlaması ve enerji karmasına eklenecek güç miktarları (GW)

\begin{tabular}{|l|c|c|c|c|}
\hline Santral Tipi & $\mathbf{2 0 2 0}$ & $\mathbf{2 0 2 1}$ & $\mathbf{2 0 2 2}$ & $\mathbf{2 0 2 3}$ \\
\hline Nükleer & - & - & - & - \\
\hline Kömür & 4,2 & 2,53 & 2,60 & 2,77 \\
\hline Doğal gaz & 3,7 & 1,99 & 2,04 & 2,19 \\
\hline Hidroelektrik & 5,79 & 3,27 & 3,38 & 3,64 \\
\hline Rüzgâr & 3,37 & 2,11 & 2,19 & 2,32 \\
\hline Güneş & 2,47 & 1,49 & 1,53 & 1,63 \\
\hline Jeotermal & 2,49 & 1,55 & 1,61 & 1,74 \\
\hline Diğer (Atık vb) & 1,86 & 1,18 & 1,19 & 1,28 \\
\hline TOPLAM & 23,87 & 14,12 & 14,54 & 15,56 \\
\hline
\end{tabular}

Buradan elde edilen sonuçlara göre kapasite artırımı veya yeni santral kurulması karar vericilerin değerlendirmesine bağlıdır. Çalışmada Akkuyu Nükleer Santrali 2023 yılı itibari ile portföye dâhil edilmiştir.

Uygulanan yöntemin sonuçlarına göre 2019-2023 yılları arasındaki elektrik üretim portföyündeki planlanan değişim Şekil 2'de verilmiştir. 


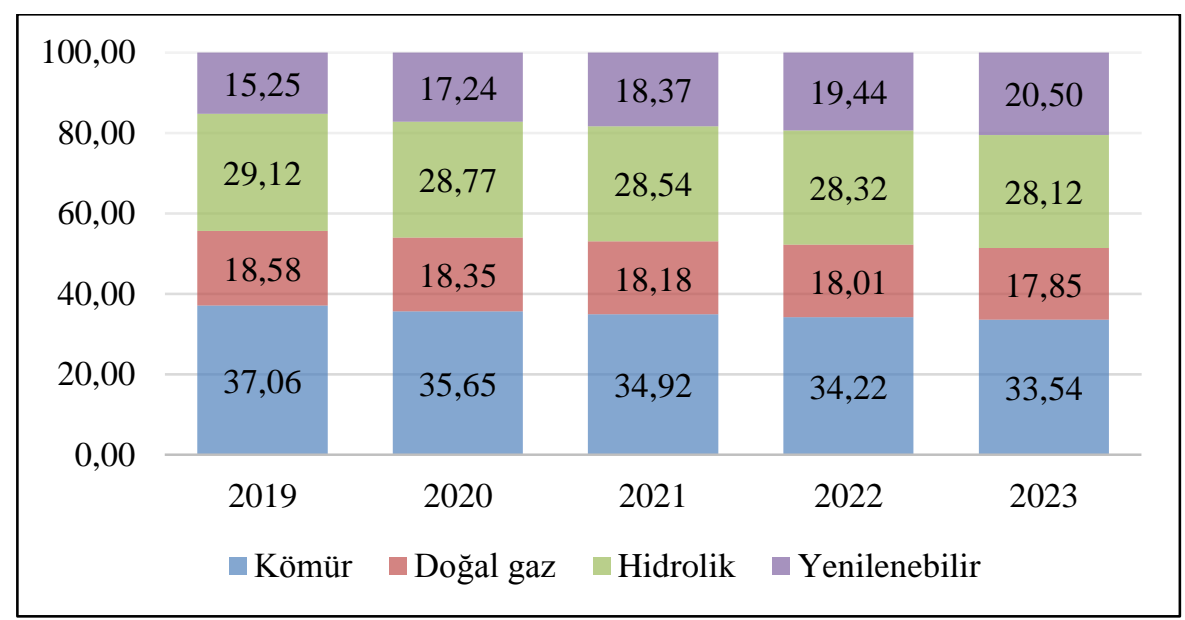

Şekil 2. 2019-2023 yılları arasında enerji karmasındaki değişim

Analiz sonucuna ve mevcut stratejilere göre 2019 yılından 2023 yılına kadar elektrik üretim karmasında yenilenebilir (hidroelektrik hariç) enerjinin payı $\% 5,25$ oranında artmış, hidroelektrik $\% 1$, doğal gaz \%0,73 ve kömür \%3,52 oranında azalmıştır (Şekil 2).

Türkiye Cumhuriyeti Enerji ve Tabii Kaynaklar Bakanlığg'nın stratejik hedefleri ve elektrik talep projeksiyonları göz önüne alındığında 2019-2039 yılları arasında elektrik üretim karmasının değişimi Çizelge 23'de verilmiştir [66].

20 yıllık planlama sürecinde baz yıl olarak kabul edilen 2019 y1lı ile hedef y1l olarak belirtilen 2039 yılları arasındaki nihai üretim değişimi Çizelge 24'de verilmiştir.

Çizelge 23. 2019-2039 yılı elektrik üretim karmasındaki değişimler (\%)

\begin{tabular}{|l|c|c|c|c|c|c|c|c|c|c|c|}
\hline & $\mathbf{2 0 1 9}$ & $\mathbf{2 0 2 0}$ & $\mathbf{2 0 2 1}$ & $\mathbf{2 0 2 2}$ & $\mathbf{2 0 2 3}$ & $\mathbf{2 0 2 4}$ & $\mathbf{2 0 2 5}$ & $\mathbf{2 0 2 6}$ & $\mathbf{2 0 2 7}$ & $\mathbf{2 0 2 8}$ & $\mathbf{2 0 2 9}$ \\
\hline Nükleer & 0,00 & 0,00 & 0,00 & 0,00 & 0,00 & 0,66 & 1,22 & 1,74 & 2,23 & 2,70 & 3,14 \\
\hline Kömür & 37,06 & 35,65 & 34,92 & 34,22 & 33,54 & 32,80 & 32,18 & 31,60 & 31,07 & 30,55 & 30,06 \\
\hline Doğal gaz & 18,58 & 18,35 & 18,18 & 18,01 & 17,85 & 17,60 & 17,41 & 17,21 & 17,04 & 16,87 & 16,71 \\
\hline Hidroelektrik & 29,12 & 28,77 & 28,54 & 28,32 & 28,12 & 27,77 & 27,47 & 27,19 & 26,94 & 26,70 & 26,46 \\
\hline Rüzgar & 9,72 & 10,04 & 10,24 & 10,44 & 10,62 & 10,71 & 10,78 & 10,84 & 10,90 & 10,96 & 11,01 \\
\hline Güneş & 0,08 & 0,82 & 1,22 & 1,60 & 1,97 & 2,23 & 2,45 & 2,65 & 2,84 & 3,02 & 3,19 \\
\hline Jeotermal & 3,72 & 4,21 & 4,49 & 4,76 & 5,02 & 5,20 & 5,34 & 5,48 & 5,61 & 5,73 & 5,84 \\
\hline Diğer(Atık vb) & 1,72 & 2,16 & 2,42 & 2,65 & 2,89 & 3,03 & 3,16 & 3,28 & 3,38 & 3,49 & 3,59 \\
\hline & & & & & & & & & & & \\
\hline & & $\mathbf{2 0 3 0}$ & $\mathbf{2 0 3 1}$ & $\mathbf{2 0 3 2}$ & $\mathbf{2 0 3 3}$ & $\mathbf{2 0 3 4}$ & $\mathbf{2 0 3 5}$ & $\mathbf{2 0 3 6}$ & $\mathbf{2 0 3 7}$ & $\mathbf{2 0 3 8}$ & $\mathbf{2 0 3 9}$ \\
\hline Nükleer & & 3,54 & 3,97 & 4,34 & 4,68 & 5,00 & 5,30 & 5,60 & 5,88 & 6,13 & 6,37 \\
\hline Kömür & & 29,60 & 29,06 & 28,65 & 28,28 & 27,93 & 27,59 & 27,26 & 26,96 & 26,69 & 26,42 \\
\hline Doğal gaz & & 16,56 & 16,43 & 16,29 & 16,17 & 16,05 & 15,94 & 15,84 & 15,74 & 15,65 & 15,56 \\
\hline Hidroelektrik & & 26,25 & 26,07 & 25,88 & 25,70 & 25,53 & 25,37 & 25,21 & 25,07 & 24,94 & 24,81 \\
\hline Rüzgar & & 11,06 & 11,11 & 11,16 & 11,20 & 11,24 & 11,28 & 11,31 & 11,35 & 11,38 & 11,41 \\
\hline Güneş & & 3,35 & 3,49 & 3,63 & 3,77 & 3,89 & 4,01 & 4,12 & 4,23 & 4,33 & 4,42 \\
\hline Jeotermal & & 5,95 & 6,08 & 6,18 & 6,27 & 6,35 & 6,43 & 6,51 & 6,58 & 6,65 & 6,71 \\
\hline Diğgr(Atık vb) & & 3,68 & 3,79 & 3,87 & 3,94 & 4,01 & 4,08 & 4,14 & 4,20 & 4,25 & 4,31 \\
\hline
\end{tabular}


Çizelge 24. 2019 ve 2039 yılları elektrik üretim miktarları

\begin{tabular}{|l|c|c|}
\hline Santral Tipi & $\begin{array}{c}\mathbf{2 0 1 9} \\
(\mathbf{G W})\end{array}$ & $\begin{array}{c}\mathbf{2 0 3 9} \\
\text { (GW) }\end{array}$ \\
\hline Nükleer & 0 & 38,035 \\
\hline Kömür & 113,118 & 157,796 \\
\hline Doğal gaz & 56,703 & 92,924 \\
\hline Hidroelektrik & 88,886 & 148,168 \\
\hline Rüzgar & 29,673 & 68,120 \\
\hline Güneş & 241 & 26,385 \\
\hline Jeotermal & 11,363 & 40,073 \\
\hline Diğer (Atık vb) & 5,258 & 25,718 \\
\hline TOPLAM & 305,241 & 597,219 \\
\hline
\end{tabular}

\section{SONUÇ VE TARTIŞMA}

Çok Kriterli Karar Verme Yöntemleri enerji planlama çalışmalarında sıklıkla tercih edilen yöntemlerdir [1, 3, 19, 21]. ÇKKV'de yöntemlerin büyük bir bölümü ağıllıkların hesaplanması süreçlerinde öznellik içermektedir [43]. Bu sebeple çalışmada AHS'nin matematiksel metodolojisinden faydalanılmakla birlikte ortalamadan sapmaları baz alan bir veri önişleme tekniği önerilmiştir. Bu veri önişleme tekniği alt kriterlerin gerçek değerlerinin karşılaştırılması esasını temel alarak her bir alternatif için alt kriterlere ödül ve ceza puanları verilmesini sağlamıştır. Böylece yöntem Türkiye Cumhuriyeti Enerji ve Tabii Kaynaklar Bakanlığı'nın stratejik planları ve kriterlerin gerçek değerlerine yönelik bir çözüm üretmiştir.

Elde edilen sonuçlar dünya genelinde oluşturmuş projeksiyonlara göre yenilenebilir enerji kaynakları kullanımında daha iyimser bir Çizelge ortaya koymaktadır. U.S. Energy Information Administration Office of Energy Analysis (EIA)'nın raporuna göre dünyada yenilenebilir enerji kaynakları (hidroelektrik dâhil), 2018-2050 döneminde yılda ortalama \%3,6 artarak en hızlı büyüyen elektrik üretim kaynağıdır [56,67]. Çalışmanın sonucuna göre Türkiye'de 2019-2039 döneminde yenilenebilir enerji kaynaklarının (hidroelektrik dâhil) yılda ortalama $\% 6,08$ artış göstermesi beklenmektedir. Birçok ülkede olduğu gibi Türkiye'de de teknolojik gelişmeler ve mevcut devlet teşvikleri artan yenilenebilir enerji kaynak kullanımların desteklemektedir.

2050'de Çin, Hindistan, OECD, Avrupa ve ABD dünyadaki yenilenebilir enerji üretiminin neredeyse \%75'ine sahiptir. $\mathrm{Bu}$ bölgelerdeki büyüme hem politikalardan hem de Hindistan ve Çin'de yeni nesil kaynaklara olan talebin artmasindan kaynaklanmaktadır [56].

Dünyada elektrik üretimindeki doğal gaz kullanımının 2018'den 2050'ye kadar y1lda ortalama $\% 1,5$ oranında artacağı öngörülmektedir. Çalışmanın sonucuna göre Türkiye'de bu oranın yılda ortalama $\% 3,04$ olarak gerçekleşmesi beklenmektedir.

Kömür yakıtlı santrallerin elektrik üretimindeki payı 2018 'de \%35'ten toplam üretim arttıkça 2050'ye kadar \%22'ye düşeceği öngörülmektedir [56]. Bu araştırmanın en önemli sonuçlarından birisi olarak, Türkiye'de 2019 yllında elektrik üretim karması içinde kömürün payı \%37 iken 2039 yilında bu payın $\% 26,42$ ye düşeceği öngörülmektedir.

Türkiye projeksiyonlarına bakıldığında fosil yakıtlı kaynakların sürdürülebilir ve çevre dostu olmadığı değerlendirilmektedir. Fakat artan enerji ihtiyacı, elektrik üretiminde bir süre daha fosil yakttlı enerji kullanımını zorunlu kılmaktadır. Gelecekte yapılacak çalışmalarda fosil yakıtlı enerji kullanımı ile ilgili sürelerinde bu planlamaya dâhil edilmesi söz konusu sürenin netleştirilebilmesine katkı sağlayacaktır.

Sonuç olarak, yapılan planlama dışa bağımlılık oranını, fosil yakıt kullanım oranını ve emisyon değerlerini düşürürken, yenilenebilir enerji kaynaklarının kullanımını, istihdam potansiyelini ve arz güvenliğini arttırmaktadır.

\section{KAYNAKLAR}

1. Mansur, E.T., 2008. Measuring Welfare in Restructured Electricity Markets. The Review of Economics and Statistics, 90(2), 369-386.

2. Kurlinski, R.E., Lave, L., Ilic, M.D., 2008. Creating Reliability Choice: How Building Less Reliability into Electric Power Grids Could Improve the Welfare of all Customers. In 2008 IEEE Power and Energy Society General 
Meeting-Conversion and Delivery of Electrical Energy in the $21^{\text {st }}$ Century (1-8). IEEE.

3. Özcan, E.C., Ünlüsoy, S., Tamer, E., 2017. ANP ve TOPSIS Yöntemleriyle Türkiye'de Yenilenebilir Enerji Yatırım Alternatiflerinin Değerlendirilmesi. Selçuk Üniversitesi Mühendislik, Bilim ve Teknoloji Dergisi, 5(2), 204-219.

4. Ürün, E., Soyu, E., 2016. Türkiye'nin Enerji Üretiminde Yenilenebilir Enerji Kaynakları Üzerine Bir Değerlendirme. Dumlupinar University Journal of Social Science/Dumlupinar Üniversitesi Soysyal Bilimler Dergisi.

5. Çoban, O., Kılınç, N.Ş., 2016. Enerji Kullanımının Çevresel Etkilerinin İncelenmesi. Marmara Coğrafya Dergisi, (33), 589-606.

6. Bayrak, M., Esen, Ö., 2014. Türkiye'nin Enerji Açığı Sorunu ve Çözümüne Yönelik Arayışlar. Ataturk University Journal of Economics ve Administrative Sciences, 28(3).

7. Furuncu, Y., 2016. Türkiye'nin Enerji Bağımlılığ ve Akkuyu Nükleer Enerji Santralı. Fen Bilimleri Dergisi (CFD), 37.

8. Temurçin, K., Aliağaoğlu, A., 2003. Nükleer Enerji ve Tartışmalar Işığında Türkiye'de Nükleer Enerji Gerçeği. Coğrafi Bilimler Dergisi, $1(2), 25-39$.

9. Wang, J.J., Jing, Y.Y., Zhang, C.F., Zhao, J.H., 2009. Review on Multi-criteria Decision Analysis Aid in Sustainable Energy Decision-making. Renewable and Sustainable Energy Reviews, 13(9), 2263-2278.

10. Lin, Y., Luo, H., Wang, D., Guo, H., Zhu, K., 2017. An Ensemble Model Based on Machine Learning Methods and Data Preprocessing for Short-term Electric Load Forecasting. Energies, 10(8), 1186

11. Zhang, Z., Hong, W.C., 2019. Electric Load Forecasting by Complete Ensemble Empirical Mode Decomposition Adaptive Noise and Support Vector Regression with Quantum-based Dragonfly Algorithm. Nonlinear Dynamics, 98(2), 1107-1136.

12. Metaxiotis, K., Kagiannas, A., Askounis, D., Psarras, J., 2003. Artificial Intelligence in Short Term Electric Load Forecasting: a State-of-the-art Survey for the Researcher. Energy Conversion and Management, 44(9), 1525-1534.
13. Alfares, H.K., Nazeeruddin, M., 2002. Electric Load Forecasting: Literature Survey and Classification of Methods. International journal of Systems Science, 33(1), 23-34.

14. Park, D.C., El-Sharkawi, M.A., Marks, R.J., Atlas, L.E., Damborg, M.J., 1991. Electric Load Forecasting Using an Artificial Neural Network. IEEE transactions on Power Systems, 6(2), 442-449.

15. Roques, F.A., Newbery, D.M., Nuttall, W.J., 2008. Fuel Mix Diversification Incentives in Liberalized Electricity Markets: A MeanVariance Portfolio Theory Approach. Energy Economics, 30(4), 1831-1849.

16. Campbell, C.J., Duncan, R.C., 1988. The Coming Oil Crisis. Brentwood, Essex, England: MultiScience Publishing.

17. Salameh, M.G., 2001. A Third Oil Crisis?. Survival, 43(3), 129-144.

18. Karagöl, E., Erbaykal, E., Ertuğrul, H.M., 2007. Türkiye'de Ekonomik Büyüme ile Elektrik Tüketimi İlişkisi: Sınır Testi Yaklaşımı.

19. Cohen, G., Joutz, F., Loungani, P., 2011. Measuring Energy Security: Trends in the Diversification of Oil and Natural Gas Supplies. Energy Policy, 39(9), 4860-4869.

20. Rugman, A.M., $1979 . \quad$ International Diversification and the Multinational Enterprise.

21. Fidan, Ü., Atak, M., 2020. Elektrik Üretim Teknolojileri Özelinde Çok Kriterli Karar Verme Yöntemleri Sonuçlarının Karşılaştırılması, Enerji Bilimlerinde Güncel Araştırmalar, Ankara: Iksad Yayınevi.

22. Şengül, Ü., Eren, M., Shiraz, S.E., Gezder, V., Şengül, A.B., 2015. Fuzzy TOPSIS Method for Ranking Renewable Energy Supply Systems in Turkey. Renewable Energy, 75, 617-625.

23. Baltuttis, D., Töppel, J., Tränkler, T., Wiethe, C., 2020. Managing the Risks of Energy Efficiency Insurances in a Portfolio Context: An Actuarial Diversification Approach. International Review of Financial Analysis, 101313.

24. Martins, F., Felgueiras, C., Smitkova, M., Caetano, N., 2019. Analysis of Fossil Fuel Energy Consumption and Environmental Impacts in European Countries. Energies, 12(6), 964.

25. Lak Kamari, M., Isvand, H., Alhuyi Nazari, M., 2020. Applications of Multi-Criteria DecisionMaking (MCDM) Methods in Renewable Energy 
Development: A Review. Renewable Energy Research and Application, 1(1), 47-54.

26. Stein, E.W., 2013. A Comprehensive Multicriteria Model to Rank Electric Energy Production Technologies, Renew. Sustain. Energy Rev. 22, 640-654.

27. Zavadskas, E.K., Turskis, Z., Kildienè, S., 2014. State of Art Surveys of Overviews on MCDM/MADM Methods. Technological and Economic Development of Economy, 20(1), 165-179.

28. Lee, A.H., Chen, H.H., Kang, H.Y., 2009. Multicriteria Decision Making on Strategic Selection of Wind Farms. Renewable Energy, 34(1), 120-126.

29. Atilgan, B., Azapagic, A., 2016. An Integrated Life Cycle Sustainability Assessment of Electricity Generation in Turkey, Energy Pol. 93, 168-186.

30. Saaty, T.L., 1980. The Analytical Hierarchy Process, Planning, Priority. Resource allocation. RWS publications, USA.

31. Saaty, T.L., 1988. What is the Analytic Hierarchy Process?. In Mathematical models for decision support. Springer, Berlin, Heidelberg, 109-121.

32. Gabus, A., Fontela, E., 1972. World Problems, an Invitation to Further Thought Within the Framework of DEMATEL. Battelle Geneva Research Center, Geneva, Switzerland, 1-8.

33. Roy, B., Bertier, P., 1968. La Methode ELECTRE. Revue d'Informatique et. de Recherche Operationelle (RIRO), 8, 57-75.

34. Fishburn, P.C., 1974. Exceptional PaperLexicographic Orders, Utilities and Decision Rules: A Survey. Management Science, 20(11), 1442-1471.

35. Brans, J.P., 1982. L’ingénierie de la Décision: L'élaboration D'instruments D'aide a la Décision. Université Laval, Faculté des Sciences de L'administration.

36. Churchman, C.W., Ackoff, R.L., 1954. An Approximate Measure of Value. Journal of the Operations Research Society of America, 2(2), 172-187.

37. Yoon, K., 1987. A Reconciliation Among Discrete Compromise Solutions. Journal of the Operational Research Society, 38(3), 277-26.

38. Zavadskas, E.K., Turskis, Z., 2010. A New Additive Ratio Assessment (ARAS) Method in Multicriteria Decision-making. Technological and Economic Development of Economy, 16(2), 159-172.

39. Zavadskas, E.K., Kaklauskas, A., 1996. Determination of an Efficient Contractor by Using the New Method of Multicriteria Assessment. In International Symposium for "The Organization and Management of Construction". Shaping Theory and Practice, 2, 94-104.

40. Brauers, W.K., Zavadskas, E.K., 2006. The MOORA Method and its Application to Privatization in a Transition Economy. Control and Cybernetics, 35, 445-469.

41. Keršuliene, V., Zavadskas, E.K., Turskis, Z., 2010. Selection of Rational Dispute Resolution Method by Applying New Step-wise Weight Assessment Ratio Analysis (SWARA). Journal of Business Economics and Management, 11(2), 243-258.

42. Zavadskas, E.K., Turskis, Z., Antucheviciene, J., Zakarevicius, A., 2012. Optimization of Weighted Aggregated Sum Product Assessment. Elektronika ir elektrotechnika, 122(6), 3-6.

43. Wang, T.C., Lee, H.D., 2009. Developing a Fuzzy TOPSIS Approach Based on Subjective Weights and Objective Weights. Expert Systems with Applications, 36(5), 8980-8985.

44. Yang, K., Ding, Y., Zhu, N., Yang, F., Wang, Q., 2018. Multi-criteria Integrated Evaluation of Distributed Energy System for Community Energy Planning Based on Improved Grey Incidence Approach: A Case Study in Tianjin. Applied Energy, 229, 352-363.

45. Özcan, E.C., Erol, S., 2013. Türkiye'de Elektrik Üretim Planlaması için Çok Amaçlı Bir Karışık Tam Sayılı Doğrusal Programlama Modeli, Selcuk Univ. J. Eng. Sci. Tech., 1(1), 41-54.

46. Alanne, K., Salo, A., Saari, A., Gustafsson, S.I., 2007. Multi-criteria Evaluation of Residential Energy Supply Systems. Energy and buildings, 39(12), 1218-1226.

47.https://enerjiapi.etkb.gov.tr//Media/Dizin/EIGM/R aporlar/Enerji_Talep_Projeksiyonu/114176turkiye_elektrik_enerjisi_talep_projeksiyonu _raporu.pdf (Erişim Tarihi: 01.08.2020)

48. Millet, I., Saaty, T.L., 2000. On the Relativity of Relative Measures-accommodating Both Rank Preservation and Rank Reversals in the AHP. 
European Journal of Operational Research, 121(1), 205-212.

49. Leccese, F., Salvadori, G., Rocca, M., Buratti, C., Belloni, E., 2020. A Method to Assess Lighting Quality in Educational Rooms Using Analytic Hierarchy Process. Building and Environment, $168,106501$.

50. Lin, Y.C., Chen, T., 2020. A Multibelief Analytic Hierarchy Process and Nonlinear Programming Approach for Diversifying Product Designs: Smart Backpack Design as an Example. Proceedings of the Institution of Mechanical Engineers, Part B: Journal of Engineering Manufacture, 234(6-7), 1044-1056.

51. Han, Y., Zhou, R., Geng, Z., Bai, J., Ma, B., Fan, J., 2020. A Novel Data Envelopment Analysis Cross-model Integrating Interpretative Structural Model and Analytic Hierarchy Process for Energy Efficiency Evaluation and Optimization Modeling: Application to Ethylene Industries. Journal of Cleaner Production, 246, 118965.

52. Yüncü, V., Koparal, C., 2019. Is Cultural Environment a Determinant of Perceived Corporate Reputation?, Journal of Business Research- Turk, 11 (2), 1044-1056.

53. Kapasite Ölçümleri https://seffaflik.epias.com.tr/transparency/uretim/ planlama/kgup.xhtml (Erişim Tarihi: 01.08.2020)

54. Teiaş Elektrik Üretim Tüketim Raporları, 2020. https://www.teias.gov.tr/tr/elektrik-istatistikleri (Erişim Tairihi: 11.07.2020)

55. Easterling, R.G., 1979. Statistical Analysis of Power Plant Capacity Factors (Vol. 382). Nuclear Regulatory Commission, Office of Management and Program Analysis, Division of Technical Support, Applied Statistics Branch.

56. Eia Report, 2019. International Energy Outlook 2019 with Projections to 2050, U.S. Energy Information Administration.

57. Eia Report, 2020. Capital Cost and Performance Characteristic Estimates for Utility Scale Electric Power Generating Technologies, U.S. Energy Information Administration.

58. Krishna, S.M., Mahapatra, S., Raj, S., Daya, J.F., 2020. Estimation of Simple, Energy and Carbon Payback Periods of a $1 \mathrm{MWp}$ Ground-Mounted Solar PV. Innovation in Electrical Power Engineering, Communication, and Computing
Technology: Proceedings of IEPCCT 2019, 630, 439.

59. Fernández, J.C.R., 2019. Integration Capacity of Geothermal Energy in Supermarkets Through Case Analysis. Sustainable Energy Technologies and Assessments, 34, 49-55.

60. Dümenli, Ş., 2019. Rüzgar ve Güneş Enerjisi Santrali Yatırımlarının ve İşletme Faaliyetlerinin Tms/tfrs Çerçevesinde Muhasebeleştirilmesi. (Yüksek Lisans Tezi)

61. Yıldırım, H.H., 2017. Rüzgâr Enerjisi Santral Yatırımlarında Geri Ödeme Süresinin Monte Carlo Simülasyonu ile Belirlenmesi. Institute of Business Administration-Management Journal/İsletme İktisadi Enstitüsü Yönetim Dergisi, (82).

62. Karaman, G., 2015. Enerji İhtiyacının Karşılanmasında Doğalgaz ve Rüzgâr Kaynaklı Enerji Çevrim Santralleri; Yatırımlar Üzerine Stratejik Bir Analiz (Master's thesis, Güven Karaman).

63. Kumar, R., Sharma, A.K., Tewari, P.C., 2015. Cost Analysis of a Coal-fired Power Plant Using the NPV Method. Journal of Industrial Engineering International, 11(4), 495-504.

64. Weißbach, D., Ruprecht, G., Huke, A., Czerski, K., Gottlieb, S., Hussein, A., 2013. Energy Intensities, EROIs (energy Returned on Invested), and Energy Payback Times of Electricity Generating Power Plants. Energy, 52, 210-221.

65. Maqbool, U., Tyagi, A., Tyagi, V.V., Kothari, R., 2020. Optimization of the Renewable-energybased Micro-grid for Rural Electrification in Northern Region of India. Clean Technologies and Environmental Policy, 1-12.

66. https://sp.enerji.gov.tr/ETKB_2019_2023_Stratej ik_Plani.pdf (Erişim Tairihi: 01.08.2020)

67. Bayer, P., Kennedy, R., Yang, J., Urpelainen, J., 2019. The Need for Impact Evaluation in Electricity Access Research. Energy Policy, 137, 111099. 